\title{
DR-40. SYNTHESIS AND ANTIMICROBIAL ACTIVITY OF BIS(AZOLYL) UREA DERIVATIVES
}

\author{
K. Narendra babu ${ }^{1}$, T. Rekha ${ }^{1}$, G. Sravya ${ }^{2}$, V. Padmavathi ${ }^{1}$, G. V. Zyryanov ${ }^{2,3}$ \\ ${ }^{1}$ Department ofChemistry, Sri Venkateswara University, Tirupati, \\ Andhra Pradesh, 517502, India \\ ${ }^{2}$ Ural Federal University of the first President of Russia B. N. Yeltsin, \\ Mira St., 19, Yekaterinburg, 620002, Russia \\ ${ }^{3}$ I. Ya. Postovsky Institute of Organic Synthesis UB RAS, \\ S. Kovalevskoy/Akademicheskaya St., 20/22, Yekaterinburg, 620990, Russia \\ E-mail: vkpuram2001@yahoo.com
}

A variety of bis(azolyl) urea derivatives were prepared by the reaction of methyl benzazoyl carbamates with azolyl amines in the presence of mild base and studied their antimicrobial activity. The presence of electron donating substituents on the aromatic ring enhanced the activity. Methoxy substituted benzothiazolyl thiazolyl urea, benzothiazolyl imidazolyl urea and benzimidazolyl thiazolyl urea displayed prominent antibacterial activity against Bacillus subtilis. Benzothiazolyl imidazolyl urea and methyl substituted benzimidazolyl imidazolyl urea showed good antifungal activity against Aspergillus niger.

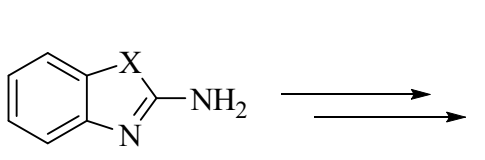<smiles>[Y]c1c[Y](NC(=O)Nc2[X]c3ccccc3n2)[nH]1</smiles>

$$
\begin{aligned}
& \text { Ar - a) } \mathrm{H} \\
& \text { b) } \mathrm{Me} \\
& \text { c) } \mathrm{OMe}
\end{aligned}
$$

